\title{
O FENÔMENO COLONIAL ENTRE A BRUXARIA E A TEORIA CRÍTICA. PENSAR ALIANÇAS A PARTIR DO XAMANISMO MAPUCHE. 1
}

LUCAS DA COSTA MACIEL ${ }^{2}$

USP, BRASIL

RESUMO: A intenção deste artigo é produzir um contraste comparativo entre dois conjuntos de teorias em torno daquilo que se conhece como o fenômeno colonial: o "pensamento crítico", por um lado, e a "teoria Mapuche", por outro. Desta comparação, evidenciaremos uma série de pressupostos que as animam, assemelhando-as e diferenciando-as em diferentes termos. A partir dai argumentaremos a necessidade de que a teoria crítica abra espaço em seu léxico de mundo para as teorias daqueles que consideram ser "povos colonizados" ou "subalternos", a depender dos autores. Tal abertura corresponderia à possibilidade de constituir alianças contra o colonialismo, um fenomeno reconhecidamente multifacetado. Para isso, nos valeremos de uma discussão etnográfica sobre as noções Mapuche de saúde e doença, entre outras coisas.

PALAVRAS-CHAVE: Ontologismo; Decolonialismo; Xamanismo.

\begin{abstract}
The intention of this article is to produce a comparative contrast between two sets of theories around what is known as the colonial phenomenon: "critical thinking", on the one hand, and the "Mapuche theory", on the other. From this comparison, we will show a series of assumptions that animate each one of these theories, resembling and differentiating them in different terms. From this we will argue the need for critical theory to open space in its lexicon of the world for the theories of those who it considers to be "colonized peoples" or "subalterns" depending on the authors. Such an opening would correspond to the possibility of forming alliances against colonialism, an admittedly multifaceted phenomenon. For this, we will use an ethnographic discussion about the Mapuche notions of health and disease, among other things.
\end{abstract}

KEYWORDS: Ontology, Decolonialism; Shamanism.

\footnotetext{
1 Agradeço a Fundação de Amparo à Pesquisa do Estado de São Paulo (FAPESP) pela bolsa de doutoramento que torna possível esta pesquisa (Processo 2018/00894-5).

${ }^{2}$ Doutorando em Ciência Social (Antropologia Social) e pesquisador do Centro de Estudos Ameríndios (Universidade de São Paulo, Brasil) E-mail: lucas.maciel@usp.br
} 


\section{Introdução}

No pensamento social latino-americano, poucos temas renderam tanta exploração quanto o fenômeno colonial. Do surgimento da teoria da dependência, no final da década de 1960, ao contemporâneo desenvolvimento da teoria decolonial, uma infinidade de autores e intelectuais se debruçaram sobre as múltiplas facetas do colonialismo para pensar as implicações do fenômeno na América Latina para além da sua concepção mais tradicional, que o entende como o controle territorial e administrativo direto de uma colônia por uma metrópole, aquilo que Mignolo (2017, p. 2) chama de "colonialismos históricos". Quando se pensa sobre a dita trajetória de pensamento, longe de se obter uma única teoria conclusiva, a impressão que se tem é que o colonialismo é algo por demais complexo para que seja conclusivamente abarcado por uma única formulação, de tal modo que cada nova proposta ilumina novos problemas sem que as propostas precedentes tenham sido superadas. Isto é, trata-se de uma trajetória de pensamento espiralada, e não linear.

Ao mesmo tempo, para aqueles que se preocupam pela resistência ao fenômeno colonial - intimamente vinculado ao sistema do capital, à racionalidade moderna e às assimetrias raciais e patriarcais - a complexidade representada, tanto pelo problema, quanto pela crítica a ele, implica que as lutas anticoloniais devem também ser multifacetadas, com muitos matizes e frentes, atuando de forma tão molecular quanto as formas de alcance do fenômeno. No entanto, e apesar da frutífera produção teórica sobre o tema, sobretudo no campo que aqui chamaremos de "pensamento crítico", pouco espaço é concedido às teorias nativas daqueles que emergem como alguns dos "sujeitos subalternos" do colonialismo na América Latina, os povos indígenas ${ }^{3}$.

Neste ensaio, minha intenção é realizar um experimento conformado de duas etapas. A primeira está em, ainda que de sobrevoo, valer-me das relações de semelhanças conceituais entre três vertentes daquilo que estou chamando de "pensamento crítico", todas amplamente replicadas e desdobradas por analistas latino-americanos - a decolonialidade ${ }^{4}$, a teoria da acumulação por espoliação ${ }^{5}$ e o marxismo feminista de Silvia Federici (2017), as três de tradição marxista -, para produzir uma síntese contrastiva e uma comparação de pressupostos e de acoplamento com outro tipo de pensamento, um de origem ameríndio, especificamente, com a teoria Mapuche sobre o awinkamiento, que explicaremos mais adiante, para aproximá-la ao fenômeno colonial.

Nossa aposta é que entre as três vertentes críticas antes indicadas existe uma certa plasticidade conceitual compartilhada, efeito de um

\footnotetext{
${ }^{3}$ Talvez as grandes exceções sejam os trabalhos de Taussig $(1993,2010)$, ainda que a postura do autor não seja simétrica em relação às teorias nativas que encontra sobre a mercadoria e o colonialismo, entre outras coisas.

${ }^{4}$ Refiro-me às produções inaugurais de Quijano (2000a, b), Mignolo (1995, 2007, 2017), Dussel (2005, 2008), Castro-Gómez e Grosfoguel (2007) Maldonado-Torres (2008) e Walsh (2013, 2017, 2008).

${ }^{5}$ Conceito cunhado por Harvey (2003), mas que relacionaremos com a noção de acumulação primitiva, de Marx (2011).
} 
mesmo acervo de realidade que permite pensar e criticar o mundo a partir de uma gramática partilhada de problemas e possibilidades argumentativas. Se pudermos retomar as metáforas contrastivas de Strathern (2009), diríamos que as três vertentes são formuladas a partir da "forma-mercadoria". Veremos, no entanto, que a tese de Silvia Federici opera uma abertura que as demais produções críticas não fazem, de tal modo que a utilizaremos, junto com a crítica de Rivera Cusicanqui ao decolonialismo, para mediar a passagem à segunda etapa do nosso experimento: apresentar a teoria Mapuche em torno daquilo que chamamos de colonialismo e de Estado-nação. Este exercício nos forçará a discutir o estatuto da realidade e a necessidade de ampliar a aliança contra o capitalismo colonial e moderno, conectando-nos, ademais, com a aposta da Antropologia contemporânea pelo ontologismo (cf. HOLBRAAD; PEDERSEN, 2017) e pela cosmopolítica (cf. DE LA CADENA, 2010; LATOUR, 2007; LIMA, 2011 ; SCHAVELZON, 2016; STENGERS, 2007; entre outros).

A intenção é invocar e desdobrar a relação entre os conceitos e as práticas de kalkutun e datun, que poderíamos traduzir, não sem perdas de sentido, como bruxaria e cura xamânica (BACIGALUPO, 2007), categorias que pertencem a alguns coletivos Mapuche da área rural do sul do território hoje ocupado pelo Estado chileno, para explorar a relação entre bruxaria e capitalismo, ou, antes, para a necessidade de se construir um pensamento de contra-bruxaria, uma crítica ameríndia e xamânica da captura ${ }^{6}$ capitalista e colonial que toma e encarcera corpos nativos. Neste sentido, o objetivo é menos o de constituir um artigo etnográfico do que utilizar elementos relacionais Mapuche para produzir conexões parciais de forma ensaística, atrelando seus elementos de especulação com o argumento geral que produziremos a partir das três vertentes do pensamento crítico. Tal passagem estará preocupada, ademais, com a proposta de retomar e reativar a feitiçaria anticapitalista ${ }^{7}$ (cf. PIGNARRE; STENGERS, 2005).

É preciso dizer, no entanto, que o ponto de partida para este exercício é o meu próprio lugar de jovem antropólogo que se interessa pelas ações cosmopolíticas dos coletivos ameríndios frente à política e à violência do Estado e do capital. Neste sentido, os dois conjuntos de pressupostos a serem contrastados, o da teoria crítica, por um lado, e o da teoria Mapuche, por outro, são ambos fruto de sínteses conjuntivas de uma série de construções especulativas e analíticas que só se apresentam como conjuntos a partir do contraste que aqui desejamos operar. Isto é, o que estou aqui chamando de teoria Mapuche está formada por um conjunto diverso de teorias que, entre si, são dissimilares, ainda que compartam um acervo de pressupostos sobre a realidade, aquilo que

\footnotetext{
${ }^{6}$ Por captura entendemos, aqui, a subjunção de uma força ou de um fluxo a um aparelho centralizador e sobre-codificado, tal como entendido por Deleuze e Guattari (2011).

${ }^{7}$ A proposta de retomar e reativar a feitiçaria anticapitalista, feita por Pignarre e Stengers (2005), está parcialmente inspirada no trabalho de Federici, que aqui comentaremos, e é retomada e desdobrada por autores como Vanzolini (2018), Sztutman (2018) e Flaksman (2018), entre outros, para levar a cabo conexões com teorias da etnologia, com o pensamento ameríndio e com os fundamentos das religiões de matriz africana, como o candomblé.
} 
Almeida (2013) chama de ontologia, isto é, a forma em que o mundo se compõe, se altera e se faz conhecer. O mesmo pode ser dito da síntese que operaremos entre as três vertentes do pensamento crítico antes indicados: dissimilares e concorrentes entre si.

Por fim, duas asseverações fundamentais animam este exercício. A primeira é a de que os processos aos quais dizem respeito os mundos ameríndios "[...] só podem ser entendidas como processos dos quais os índios são sujeitos, e não objetos. Se os mundos indígenas mudam como todos os mundos, aliás -, só podem mudar em seus próprios termos" (VANZOLINI, 2018, p. 326). Daí a importância das teorias nativas daqueles que tão facilmente enquadramos em nossos esquemas analíticos como os subalternos e os colonizados: elas colocam em termos ameríndios os problemas que chamamos por nomes tais como colonialismo, capitalismo, patriarcado e modernidade, entre outras coisas.

Em segundo lugar, está a premissa de, também nas palavras de Vanzolini (2018, p. 328), "resistir à tentação de achar que nós sabemos melhor do que eles o que está acontecendo, e que sabemos o que é melhor para eles [...]". Isto é, a premissa ética deste ensaio é considerar a teoria nativa Mapuche pelo que ela é, uma teoria coerente e eficaz para pensar e atuar sobre o mundo e que ocupa um lugar equivalente ao que nós concedemos, em nosso contexto acadêmico, a especulações tais como aquelas que estou chamando de pensamento crítico. A intenção do contraste que operaremos é, também, o de apresentar a teoria Mapuche da doença e da saúde como uma prática política viável e eficaz para desarmar a espoliação e a colonialidade.

A experiência Mapuche aparece aqui, então, e nos termos de Héctor Nahuelpán (2013), como um posicionamento político, enquanto seu autogoverno (autonomia) figura como uma crítica e uma contra-ação frente à subordinação colonial; isto é, um lugar produtivo desde o qual emergem e se recriam conhecimentos e outros possíveis que apontam para formas distintas de engajar-se e resultar de relações. Para tanto, retomamos a proposta cosmopolítica como um princípio metodológico e ético (cf. STENGERS, 2007) que atenta para a necessidade de entender a política Mapuche como algo que excede a nossa própria noção de política, encapsulada como está pela institucionalidade do Estado-nação (cf. DE LA CADENA, 2015).

Como na maior parte dos mundos ameríndios, a política Mapuche é a sobreposição de uma série de relações que produzem implicações diretas sobre a vida das pessoas e de eventos que resultam da ação direta de algum sujeito, humano ou não-humano. Assim, trata-se de uma política que conecta e negocia com entidades como os espíritos que conhecemos como "donos ou mestres de animais", os ancestrais, a rede de comunidades Mapuche, o Estados chileno e argentino e a sociedade winka ("não indígena"), para citar algumas. Entre o que nós poderíamos mal-chamar de "mundo espiritual" e o governo do Chile, a política Mapuche tem muitos matizes que excedem nossa concepção desencantada ou, nos termos que aqui me interessa, capturada, de política. 
Devemos compreender, portanto, o lugar da cosmopolítica como o das relações que conectam corpos e pessoas. Se o corpo Mapuche é o lugar do conflito entre a colonialidade do capital e do Estado, por um lado, e a descolonização e o seu modo de vida no Wallmapu ("território Mapuche"), por outro, é porque entre ser Mapuche ou não Mapuche encontra-se uma economia de saberes e afetos, uma teoria da pessoa e uma série de relações das quais esta emerge. Ser uma pessoa de verdade, che, requer, para os Mapuche, engajar-se e produzir relações adequadas. Veremos como isso se dá e como isso se aproxima e se distancia dos argumentos da teoria crítica.

\section{O colonialismo e a Teoria Crítica}

Segundo Quijano (2000a, p. 201), a fase atual de globalização do capital não configura um novo regime: trata-se do cúmulo de um processo cuja a origem está na própria constituição original da ordem capitalista colonial, moderna e eurocentrada ${ }^{8}$ como um padrão geopolítico de poder, e na constituição da América como um "outro", um território e uma população a serem explorados. Para o autor, o axioma fundamental da ordem que se instala com o nascimento do capital, e que se arrasta até os nossos dias, é a racialização de determinados grupos humanos. Valendo-se da raça como instrumento de classificação social, o poder global do capitalismo legitima as relações de dominação impostas pelos processos coloniais, criando e aplicando tipologias marcadas por relações de superioridade e inferioridade que "naturalizam" a posição de colonizados e colonizadores, tornando-os lugares numa estrutura fixa de dominação. Tratar-se-ia, portanto, de um mecanismo epistemológico e econômico de configuração das relações de poder. Em suas palavras,

[...] los pueblos conquistados y dominados fueron situados en una posición natural de inferioridade $y$, en consecuencia, también sus rasgos fenotípicos, así como sus descubrimientos mentales y culturales. De ese modo, raza se convirtió en el primer criterio fundamental para la distribución de la población mundial en los rangos, lugares y roles de la estructura de poder de la nueva sociedade. En otros términos, en el modo básico de clasificación social universal de la población mundial (Quijano, 2000a, p. 203).

Esta inferiorização teria permitido, segundo o autor, que se associasse a ideia de raça à divisão do trabalho, tanto local como internacionalmente ${ }^{9}$, produzindo um sistema de divisão racial que

\footnotetext{
${ }^{8} \mathrm{O}$ que o autor chama de eurocentrismo é um tipo de racionalidade específica do poder mundial capitalista, moderno e colonial.

${ }^{9}$ Este ponto é essencial à teoria pós-colonial de Spivak (2014), diga-se de passagem. A autora acusa a teoria crítica europeia, em especial o pós-estruturalismo de Foucault e Deleuze, de não reconhecer as contradições e os constrangimentos próprios do contexto colonial, de tal modo que, para a autora indiana, a teoria social
} 
permitia o controle da mão-de-obra. Ao mesmo tempo em que a Europa Ocidental emergiu como a sede do controle do mercado mundial, nas regiões não europeias, o trabalho assalariado tornou-se um privilégio dos brancos, enquanto outras populações, como as negras e as ameríndias, eram postas sob os regimes de servidão e escravidão. No nascimento da América, portanto, uma associação é operada pelo padrão poder colonialista e colonial - e sua lógica eurocentrista - entre o trabalho não remunerado e as raças inferiorizadas. O genocídio indígena ao longo dos séculos se inscreve, neste contexto, a uma associação dos ameríndios com um tipo de mão-de-obra descartável, condenada a trabalhar até à morte $^{10}$. Este argumento em torno do controle colonial do trabalho pode ser estendido também para entender os mecanismos de controle territorial, como demonstram os trabalhos de Svampa (2012) e Garibay Orozco (2010), de tal modo que territórios periféricos, tidos como selvagens, se tornam igualmente alvo de uma sobre-exploração que tende ao esgotamento completo e que, para produzir acumulação, impossibilita toda forma de vida, transformando territórios "outros" em paisagens de espoliação.

Em suma, o padrão racial de divisão do trabalho, permitindo às forças coloniais controlarem pessoas e territórios, se instaura com o nascimento do capitalismo e se mantém até nossos dias. É neste sentido que para Mignolo (2017, p. 1) "[...] a pauta oculta (e o lado mais escuro) da modernidade era a colonialidade". Nos termos do autor $(2017$, p. 2), o conceito de colonialidade "[...] nomeia a lógica subjacente da fundação e do desdobramento da civilização ocidental desde o Renascimento até hoje, da qual colonialismos históricos têm sido uma dimensão constituinte, embora minimizada". Assim, e ressoando os argumentos de Quijano, Mignolo afirma que não há modernidade sem colonialidade, e que esta última se manifesta, tanto no campo das práticas de poder econômico, quanto no do conhecimento, como uma "[...] dispensabilidade (ou descartabilidade) da vida humana, e da vida em geral [...]" (MIGNOLO, 2017 , p. 4).

Ocultar-se-ia, sob a retórica moderna, uma série de práticas econômicas que dispensam vidas humanas, enquanto um conjunto de conhecimentos vinculados à epistemologia da ciência justificariam o racismo e a inferioridade de certos grupos de pessoas, tornando-as naturalmente dispensáveis ${ }^{11}$. O processo colonial é a outra das caras da modernidade capitalista porque ele produz a figura do indígena, categoria que só existe a partir da inflexão colonial, para logo retirar dele a sua verdade inquestionável, argumentando a inevitabilidade do processo colonial enquanto sentido histórico necessário, quase "natural" (CLAROS, 2011 ). Nas palavras de Bonfil Batalla (1980, p. 230),

\footnotetext{
europeia, pretensamente universal porque se fundamenta em critérios genéricos sobre a humanidade, tais como a noção de desejo, seria uma teoria específica para as relações de poder no mundo metropolitano.

${ }^{10}$ As conexões com a noção de necropoder são, pois, evidentes (cf. MBEMBE, 2018).

${ }^{11}$ Argumentos similares ressoam, por exemplo, no pós-colonialismo de Mbembe (2018, p. 32-33), para quem, “[...] no pensamento filosófico moderno assim como na prática e no imaginário político europeu, a colônia representa o lugar em que a soberania consiste fundamentalmente no exercício de um poder à margem da lei (ab legibus solutus) e no qual a 'paz' tende a assumir o rosto de uma 'guerra sem fim'."
} 
[...] la invasión y la conquista europea de América se racionalizó a partir de una definición del indio como inferior, como naturalmente destinado a ser redimido y elevado gracias a la acción del colonizador, su superior [...] en todos los órdenes de la vida".

Daí que a teoria decolonial que se desdobra do pensamento de Quijano e Mignolo, entre outros, se coloque como uma crítica sociológica e epistemológica à colonialidade, uma das faces de um mesmo fenômeno complexo que se apresenta como capitalismo, modernidade e, a depender do autor, como patriarcado.

Também para Harvey (2003), o sistema capitalista segue funcionando através de lógicas de dominação que persistem desde o seu surgimento. Segundo o autor, a economia política do capitalismo produz o que ele chama de "acumulação por espoliação", um processo através do qual ativos públicos e comuns são encapsulados para o uso privado e lucrativo dos recursos. Tal forma de acumulação, argumenta o autor, estaria na gênese do capitalismo. Convém, então, que retomemos os argumentos de Marx (2011) sobre o fenômeno da "acumulação primitiva" que se desprende do cercamento de terras comuns na Inglaterra do século XVIII. Segundo o autor, a origem do capitalismo está na usurpação, feita à força e através de formas legais de expropriação legitimadas pelo Estado, que levou a uma transformação das relações sociais, separando os produtores diretos dos seus meios de produção. Tais meios, antes de subsistência, se transformavam em capital, e os produtores imediatos, antes vinculados à terra, tornavam-se trabalhadores assalariados. É a este processo que Marx dá o nome de acumulação primitiva. Assim, na gênese do meio de produção capitalista estariam, entre outras coisas, a privatização da terra e a sua transformação em mercadoria, bem como a expulsão violenta de populações camponesas, dois processos de apropriação de ativos que poderíamos caracterizar, sob o léxico de Quijano e Mignolo, como coloniais.

Em divergência com uma leitura da acumulação originária como um momento inicial do sistema do capital, como pareceria sugerir Marx, situa-se a ideia de que processos semelhantes àqueles que levaram à acumulação primitiva se mantêm como uma invariável na manutenção e globalização do capitalismo. Para Harvey (2003), então, o capitalismo contemporâneo continua a se expandir pela alienação de meios de produção em novas áreas, valendo-se, para tanto, da violência de instituições como o Estado. Dito em outros termos, o processo que se chamou de "acumulação primitiva" de capital é interminável e configura o devir histórico e geopolítico do próprio sistema, combinando, para tanto, forças de ordem produtiva e econômica com processos de violência política que transformam bens não mercantis em mercadoria e capitalizam processos e elementos antes externos ao próprio capital.

O ponto de partida da leitura de Harvey é a noção, defendida por Rosa Luxemburgo (1988), de que o capitalismo necessita dispor de coisas externas a si para manter-se estável. Sua face inegavelmente imperial 
estaria no fato de que as soluções a suas contradições seriam constantemente obtidas de fontes externas. Parcialmente de acordo com esse argumento, para Harvey o externo do qual depende o capitalismo é fruto de um processo de produção do outro que pode se valer tanto de um exterior pré-existente, incorporando novas regiões antes externas, como já notara Luxemburgo, quanto da produção ativa desses lugares em seu interior (HARVEY, 2003, p. 118). O próprio capitalismo seria responsável, para o autor, por produzir seu exterior na medida em que ele regurgita partes de si mesmo, como a massa de desempregados e as reservas de recursos naturais em forma de reservas ecológicas, por exemplo.

Este processo de fabricação, uma "outrização" constante, também é um argumento central do decolonialismo. Para Dussel (2005), este seria um dos núcleos da ação eurocêntrica e transmoderna da modernidade capitalista. Ela consistiria na produção de um "nós" eurocentrado e de um "outro" que corresponderia aos "povos do mundo periférico", entre outros. A modernidade é, no argumento de Dussel, a emancipação do "nós" europeu e a espoliação do "outro", algo também já explorado por Todorov (1991). Coloca-se, mais uma vez, a centralidade não só das estratégias econômicas, mas também dos recursos epistemológicos para a perpetração e a expansão do sistema. A situação colonial é também um sistema de divisão e classificação social que impede que o colonizado se coloque como sujeito de modos de vida viáveis; são pessoas negadas pela diferença colonial. Os indígenas aparecem como seres sitiados (Fanon, 2011 ): assediados por uma identidade colonial imposta que se constrói a partir do outro.

Argumenta-se, então, que as despossessões coloniais não são originárias do capitalismo, mas constitutivas dele. Neste sentido, a "acumulação por espoliação", na caracterização do capitalismo contemporâneo, consiste numa persistente e recorrente prática predatória de "acumulação primitiva", que Harvey considera, na trilha de Rosa Luxemburgo, como tendo caráter permanente.

A lógica do capital é, para Harvey, territorial, produzindo outros externos e disponíveis para serem espoliados ${ }^{12}$ - por isso o caráter de controle espaço-territorial dos Estados nacionais, instrumentos que figuram como meios necessários à acumulação do capital. O Estado emerge, então, como um administrador das condições coloniais e das relações que as materializam, produzindo, entre outras coisas, o contínuo empobrecimento dos povos colonizados, a espoliação dos seus territórios, a violência epistêmica (cf. SPIVAK, 2014) e a destruição das condições de reprodução dos seus mundos de alteridade. O Estado é, portanto, uma máquina de espoliação e de destruição de mundos (cf. DE LA CADENA, 2015; QUIJANO, 2000a). Para Mbembe (2018, p. 38), por exemplo, "a 'ocupação colonial' em si era uma questão de apreensão, demarcação e afirmação do controle físico e geográfico - inscreve sobre o terreno um

\footnotetext{
${ }^{12}$ Para O'Gorman (2014) e Mignolo (2007), a invenção da América como um novo mundo a ser explorado é a etapa inicial do capitalismo global, dando os fundamentos para a edificação do chamado "sistemamundo" colonial e capitalista (Wallerstein, 1974).
} 
novo conjunto de relações sociais e espaciais". Essa geografia do controle se daria, sobretudo, pela ação do Estado ${ }^{3}$.

Por fim, para Federici (2017), a história da formação e ascensão do capitalismo colonial está intimamente atrelada à produção do patriarcado - o controle sobre o corpo das mulheres, dos meios de reprodução social e a criação do trabalho não remunerado das mulheres -, momento que se inscreve na história da caça e da queima das bruxas na Europa e na América. Isso porque [...] a discriminação contra as mulheres na sociedade capitalista não é o legado de um mundo pré-moderno, mas sim uma formação do capitalismo, construída sobre diferenças sexuais existentes e reconstruída para cumprir novas funções sociais" (FEDERICI, 2017, p. 11). Para a autora, a perseguição e a eliminação das bruxas na formação histórica do capitalismo corresponderiam a um processo em que se segrega, se demoniza e se elimina as mulheres que resistiam ao poder do Estado e da Igreja. Segundo Federici, não seria possível compreender a acumulação primitiva e a emergência do biopoder, um conjunto de técnicas que produzem a subjugação de corpos e o controle de populações ao gerir a sua capacidade de construir vidas possíveis, sem levar em conta o quanto a formação do capitalismo, entendido como um sistema de produção e como um modelo de dominação que produz corpos capturados e controle da reprodução social, se dá sobre os corpos queimados das mulheres que resistiram a ele. É à custa dos corpos das mulheres que emerge o capitalismo e se inaugura o bipoder ${ }^{14}$.

A figura da bruxa corresponde, para a autora, à "[...] encarnação de um mundo de sujeitos femininos que o capitalismo precisou destruir: a herege, a curandeira, a esposa desobediente, a mulher que ousa viver só, a mulher obeah que envenenava a comida do senhor e incitava os escravos à rebelião" (FEDERICI, 2017, p. 24). Para Federici, como para os demais autores antes citados, a violência é a condição de existência do capitalismo em qualquer época; uma violência tripla: o controle da mãode-obra do outro, mulher e não europeu; a espoliação territorial; e a captura do processo de reprodução social. Se o subalterno é, para Spivak (2014), a medida de precaução contra o pensamento colonial da teoria social europeia, em Federici (2017) a mulher é, sob a égide do capitalismo, uma forma particular de exploração e, neste sentido, um ponto de vista a partir do qual produzir uma reconsideração histórica das relações capitalistas. Um ponto de vista que exige retomar as forças extraordinárias que se resistem à imposição de um modo de vida concebido em termos capitalistas, modernos, coloniais e patriarcais. É preciso, segundo a autora, retornar às lutas pelo comum e contra a submissão capitalista das mulheres, dentro e fora da Europa, porque elas

\footnotetext{
${ }^{13}$ É justamente pelo fato de que o Estado seja uma estrutura própria das sociedades capitalistas (e portanto, modernas e coloniais) que, para autores como Holloway (2003), a transformação social - a teleologia do pensamento crítico - não poderia passar por ele. Ainda que essa asseveração seja uma crítica anarquista à teleologia marxista, ela também é simpática ao argumento foucaultiano de que o direito soberano de matar e os mecanismos de biopoder estão inscritos na forma em que funcionam todos os Estados (cf. FOUCAULT, 1999, p. 227-232).

${ }^{14}$ Neste sentido, a teoria foucaultiana é, para Federici $(2017$, p. 35), omissiva. Na medida em que não reconhece o momento em que o biopoder é criado, tal teoria se dá à custa da caça às bruxas e do discurso sobre a demonologia no disciplinamento corporal das mulheres.
} 
apontam para um mundo extraordinário, com outras possibilidades de vida.

De forma geral, portanto, esta síntese operada, e que estamos chamando de "teoria crítica", se vale de uma crítica sociológica e historiográfica à formação do capitalismo como um processo complexo, moderno e patriarcal, para pensar a constituição das relações sociais em contextos coloniais. De forma geral, o léxico de fundo desse pensamento crítico é marxista, ainda que os decoloniais estejam especialmente influenciados pelo marxismo de Mariátegui, que, segundo Tible (2017, p. $34)$, tem como chave de análise a questão indígena ${ }^{15}$. Preocupado pelas relações de controle, pela apropriação do trabalho e pelos mecanismos de biopoder, entre outras coisas, o pensamento crítico tem como metáfora de base a forma-mercadoria, em que as pessoas e as coisas assumem a forma social de coisas (STRATHERN, 2009, p. 208). Isto é, não é preciso, para produzir pensamento, reconhecer a subjetividade e a intencionalidade daqueles sobre o qual se trata; importa o lugar que eles ocupam numa estrutura de contraste que organiza o pensamento crítico e que é anterior a eles. No pensamento crítico, pessoas são tomadas pelos lugares que ocupam numa estrutura de poder: homem/mulher, capitalista/operário, colonizador/colonizado são algumas dessas opositivas. Encontram-se entre seus pressupostos, ademais,

[...] a ideia de que pessoas podem ser menos que seres humanos; da natureza como [...] um recurso; do tipo de identidade implicado na teoria dos papéis sexuais; de atributos apropriados como se tivessem propriedades intrínsecas; do controle como o propósito da dominação, e assim por diante (STRATHERN, 2009, p. 209).

Essas noções são, de forma óbvia, desdobramentos de pressupostos de fundo sobre a organização do mundo especificamente ocidentais, alimentados, entre outras coisas, pela própria Constituição Moderna (LATOUR, 2013). E ainda que os autores se pretendam críticos às divisões ontológicas entre natureza e cultura, uma ferramenta tida por eles como colonial e patriarcal, não conseguem escapar dela. Por fim, o pensamento crítico tem como asseveração fundamental a ideia de que coisas tais como trabalho, corpo, território e reprodução social existam em si mesmas, como coisas. Veremos o quanto, na teoria Mapuche, isto que entendemos como coisas são efeitos relacionais. Isto é, as relações não incidem de fora sobre as coisas pré-existentes, mas elas são condição para que tenham lugar. Esta forma de constituir mundo se desdobra de uma relacionalidade radical, na qual entidades não são pré-existentes à

\footnotetext{
${ }^{15}$ Nas palavras de Tible (2017, p. 34), Mariátegui “[...] 'indigeniza’ Marx, ao efetuar uma espécie de 'descentralização' do marxismo, superando não o método marxista, mas a perspectiva europeia [...].” No entanto, como bem reconhece o autor, "[...] há uma certa idealização no que toca à organização política e social Inca. Mariátegui parte de uma imagem desta (entendida como comunista) compartilhada também por anarco-sindicalistas e indigenistas [...]. Mariátegui propõe uma instigante ligação entre ayllu [algo que poderíamos mal-traduzir por 'comunidade andina'] e comunismo, mas parece ignorar as diferentes formas de organização política ameríndia” (TIBLE, 2017, p. 36-37).
} 
relação, mas estas as constituem, de modo que tudo é mutuamente constituído (ESCOBAR, 2017, p. 8). Exemplos disso, na Antropologia, são as noções de pessoa fractal e partível (cf. STRATHERN, 2009; WAGNER, 2011 ) e a reinvenção do conceito de ayllu por Marisol de la Cadena (2015), entre outras coisas.

O antes indicado não elimina a centralidade do pensamento crítico na produção de resistências (epistemológicas e sociais) ao processo colonial. Revela, no entanto, que ela não condiz com a forma em que alguns povos ameríndios conformam mundo, compreendem 0 colonialismo como fenômeno equívoco e produzem resistência. Suplantar e silenciar as teorias nativas pelo nosso léxico analítico, considerando-o preciso e verdadeiro a despeito da verdade e da forma de ação e pensamento dos outros, é um tipo de "colonialismo interno" (cf. GONZÁLEZ CASANOVA, 2006; RIVERA CUSICANQUI, 2010, p. 67). Para resistir e fugir a esse perigo é preciso, então, pensar de forma extraordinária, para retomar o termo de Federici, levando a sério os mundos de alteridade e as formas em que eles produzem pensamento especulativo. Daí que a crítica de Rivera Cusicanqui ao decolonialismo seja extensível para o pensamento crítico, em geral. Segundo a autora, "no puede haber un discurso de la descolonización, una teoria de la descolonización, sin una práctica descolonizadora" (RIVERA CUSICANQUI, 2010 , p. 62). Isto porque a pulsão descolonizadora vem da coetaneidade das formas e políticas ameríndias, entre outras coisas, indicação que é também compartilhada por Nahuelpán.

A descolonização operada pelos povos indígenas, sua forma de crítica ao capitalismo e ao projeto colonial, é uma ação. Veremos como uma antropologia reversa Mapuche, uma crítica ao mundo e à forma de vida dos brancos, consiste, entre outras coisas, na prática de cura xamânica ${ }^{16}$. As análises do pensamento crítico são, como antes dito, uma crítica historiográfica e sociológica às formas do capital, do colonialismo, da modernidade e do patriarcado. Neste sentido, constituem um alerta, nos termos da nossa teoria social moderna, para a necessidade da descolonização, mas assumem nossa forma de produzir crítica: a de um argumento analítico. No entanto, estão vazios, em si mesmos, de uma prática descolonizadora tal como produzida pelos povos ameríndios. Sem prestar atenção às dinâmicas internas e às formas de produzir pensamento e ação críticas daqueles que chamamos de colonizados e subalternos, as cooptações acadêmicas terminam neutralizando a potencialidade das práticas descolonizadoras dos povos, transformandoas em um argumento historiográfico e sociológico desencantado (cf. RIVERA CUSICANQUI, 2010).

O desafio é pensar uma produção acadêmica que esmiúce o modo em que os povos ameríndios produzem crítica ao colonialismo; um discurso teórico-etnográfico sobre suas práticas de descolonização. Um discurso que diminua a velocidade em que nosso pensamento produz

\footnotetext{
${ }^{16}$ Uma antropologia dos melanésios assume, para Wagner (2012), a forma de um culto de carga. A questão é nos perguntarmos quais formas assumem a antropologia reversa dos ameríndios. Qual a forma da descolonização em termos nativos?
} 
conexões entre coisas; que crie conexões "extraordinárias" e permita vislumbrar o impensável ${ }^{17}$ ao mesmo tempo em que faz emergir novos imponderáveis, povoando a resistência de inimagináveis. Vejamos de que forma um experimento com a teoria Mapuche nos ajuda neste sendeiro.

\section{O awinkamiento colonial dos Mapuche}

Entre as comunidades rurais Mapuche do sul do Chile, a bruxaria é a causa primeira das doenças e da má sorte que acometem as pessoas (BACIGALUPO, 2007, p. 17). A kalku, a bruxa, quer que as famílias morram para que ela fique com a sua terra e os seus bens. Para tanto, ela separa o corpo (trawa) e as almas da pessoa, decompondo-a (BACIGALUPO, 2007). A püllü (alma destacável) é sequestrada e finalmente devorada por um espírito agressivo, enquanto sua $a m$, a alma imperecível que resta depois da morte, é transformada em wekuve (um espírito agressivo e perigoso), em um morto ou em um winka (um não indígena, um chileno).

Segundo Bonelli e González Gálvez (2016, p. 37-38), wekuve é um termo geral utilizado para denominar uma série de entidades cuja intenção subjetiva é, do ponto de vista dos humanos, maligna. Formado pela junção de weku-, cuja acepção literal é "fora", e pelo sufixo -ve, usado para indicar o sujeito que realiza uma ação, o wekuve poderia ser entendido como "aquele que realiza o de fora". Interessantemente, argumentam os autores, weku é a forma em que, na terminologia de parentesco Mapuche, se chama o irmão da mãe, aquele que é tradicionalmente visto como o afim por excelência, dada a regra de matrimônio com a prima cruzada matrilateral (BONELLI; GONZÁLEZ GÁLVEZ, 2016, p. 38).

Este dado é fundamental para que se compreenda o estatuto da alteridade no contexto Mapuche, especialmente tendo em vista a tese de Course (2011) sobre as relações que compõem uma pessoa de verdade, che. Segundo o autor, toda pessoa está conformada pela junção do sangue menstrual da mãe e pelo sêmen do pai. Estas substâncias conectam as pessoas aos avós paternos e aos avós maternos, de tal modo que o küpal, traduzido como descendência, é visto como a parte inata da pessoa Mapuche, estando fixo desde a concepção e funcionando como a base das relações interpessoais (COURSE, 2008, p. 303). No entanto, para que alguém seja uma pessoa de verdade, che, é necessário extrapolar as relações de descendência e produzir novas relações. Assim, "[...] são as relações criadas por vontade própria ao longo da vida que permitem a alguém ser uma pessoa" (COURSE, 2008, p. 305). Para o autor, a pessoa Mapuche tem, então, uma dinâmica centrífuga, marcada por um movimento constante para fora, orientada para o exterior e para os outros. Neste contexto, toda pessoa Mapuche é um ponto de contato entre o

\footnotetext{
${ }^{17}$ Para Ramos (2008, p. 61), o impensável é aquilo do qual não se dispõe de instrumentos de pensamento para que se torne pensável e, portanto, plausível. Para a autora, a comparação antropológica pode nos ajudar a tornar pensável o impensável.
} 
interior, marcado pela consanguinidade, e um exterior, constituído pelas relações de diferenças com amigos e afins ${ }^{18}$.

O problema que se coloca é, pois, o do lugar da afinidade potencial e dos limites transformacionais nos mundos ameríndios. Vale recordar, então, a asseveração geral de Viveiros de Castro (2001, p. 25) sobre o valor simbólico da afinidade potencial enquanto marca de alteridade, da qual a afinidade real é apenas uma expressão. No contexto Mapuche, isso corresponde a dizer que o weku, o irmão da mãe, é o paradigma das relações que constituem a pessoa; é a abertura à alteridade que faz com que alguém seja uma pessoa de verdade, cuja constituição está relacionalmente orientada para o exterior do küpal. No entanto, na atualização da afinidade potencial em real, o contato com o externo pode ser autodestrutivo se não mediado e tratado com precaução (BONELLI; GONZÁLEZ GÁLVEZ, 2016, p. 39), daí a importância da cura xamânica, como se verá.

A bruxaria da kalku e dos wekuve é um tipo de "magia simpática". A kalku envia a bruxaria, doença ou morte conectando algo que contenha a essência, a imagem ou os elementos corporais da vítima com um espírito agressivo ou com o Munche Mapu ("o inframundo"), entre outras coisas. O resultado imediato de ter sido embruxado é o surgimento de conflitos no interior dos agrupamentos de parentesco e a perda da noção de si mesmo, o que leva a pessoa Mapuche a atuar como alguém que não é che, uma pessoa de verdade, tornando-a incapaz de produzir relações efetivas. A pessoa se torna, portanto, um outro agressivo. A bruxaria é, pois, uma forma de deixar de se conhecer, um não conhecer-se a si mesmo e à sua origem que leva à perda de identidade e dos valores caros aos Mapuche, resultando, tanto no conflito e na divisão dos grupos de parentesco e das comunidades territoriais (lof), quanto a assunção do ponto de vista do outro, do afim potencial que é também um inimigo potencial, o espírito, ou wekuve. É neste sentido que o resultado da bruxaria é uma morte: morre-se como pessoa de verdade para tornar-se um morto, um chileno ou um espírito.

Como coloca Bacigalupo (2007, p. 33-34), "[...] a bruxaria Mapuche está intimamente vinculada à história do colonialismo espanhol, às missões de padres católicos, à resistência aos projetos de assimilacionismo e desenvolvimento do Estado chileno e à incorporação e ressignificação do povo Mapuche em relação aos discursos de maioria chilena". Não por acaso as acusações de bruxaria estão frequentemente associadas com o awinkamiento, um fenômeno atrelado às práticas, ações ou crenças winka, aquele que não é Mapuche (BACIGALUPO, 2007,

\footnotetext{
${ }^{18}$ Como também reconhece Course (2008, p. 300), este argumento ressoa a análise de Viveiros de Castro (2002, p. 430) sobre os dualismos concêntricos, para quem "qualquer ponto arbitrariamente escolhido do interior é um limite entre um interior e um exterior: não existe meio absoluto de interioridade". Por um lado, isso alerta para a necessidade de atentar para as fronteiras sempre movíveis do social (cf. VIVEIROS DE CASTRO, 2002, p. 297-316), enquanto por outro retoma a discussão lévi-straussiana sobre o ternarismo das estruturas duais (cf. COELHO DE SOUZA, 2013; LÉVI-STRAUSS, 1993, 2017). Não à toa, Ramos (2008, p. 61) escolhe a imagem da dobra, apresentada por Deleuze (1991) em seu estudo sobre Leibniz, para metaforizar a composição da pessoa Mapuche: uma subjetividade composta por um interior que é a dobra do exterior; a replicação do que está fora, incluindo o mundo das relações sociais, dos objetos e da "natureza".
} 
p. 19). Um embruxamento por awinkamiento, se não tratado, resulta no tornar-se winka ou espírito agressivo. Em ambos os casos, a pessoa deixa de assumir a perspectiva Mapuche, de viver e conhecer o mundo como tal, para passar a fazê-lo sob a perspectiva do Estado, seja como chileno ou como wekuve colonial; em termos mais próximos aos nossos, o awinkamiento é um processo de captura do corpo Mapuche, tornando-o domesticado ao Estado e à onto-episteme da modernidade capitalista e colonial. Tampouco é gratuito que os espíritos agressivos responsáveis pelo awinkamiento, que atacam as pessoas por convocação da bruxaria, sejam frequentemente descritos como homens brancos e latifundiários ou sereias loiras, entre outros, que portam símbolos nacionais chilenos. Aliás, quanto mais próximo alguém está dos valores nacionais chilenos, mais perigosos os espíritos coloniais se tornam para ele ou ela, de tal modo que resistir e curar-se do awinkamiento requer recobrar o conhecimento sobre si.

O awinkamiento leva à produção de relações que, desde a perspectiva Mapuche, são perigosas. A pessoa embruxada se torna cada vez mais conectada com o mundo winka e seus modos de relação. O que da perspectiva da pessoa Mapuche saudável era um "fora" com o qual se deve conectar com precauções, da perspectiva do embruxado se torna um "interior" com o qual se está intimamente atrelado. Nos termos que antes discutíamos, a bruxaria é o consumo das relações inatas que compõem o küpal, produzindo uma passagem entre mundos. A pessoa se desprende da sua comunidade de parentesco e território, deixando de reconhecê-la como tal, para ver-se como chilena (ou espírito), reconhecendo como seu, um outro mundo; aquele que, da perspectiva Mapuche, é o mundo da diferença. O embruxado se relaciona com o mundo winka não como uma diferença conectada, mas como numa relação de semelhança. Se nos mundos ameríndios existe alguma definição possível de humano, ela seria a capacidade de produzir parentesco por alianças afetivas. Neste contexto, o embruxado que se torna outro está desabilitado a fazê-lo.

O efeito dos eventos que produzem inversões de pontos de vista e o perigo que este processo implica nos mundos ameríndios, guardadas suas especificidades, é brilhantemente tratado, para o caso do Yudjá, por Lima (1996). Em mundos marcados pelo potencial da transformação, esse problema diz respeito à interpenetração entre o "eu" e o "outro" em relações de subjetividades pronominais (cf. VIVEIROS DE CASTRO, 1996, 2015), sem as quais, como vimos, ninguém se torna uma pessoa efetiva. Nos termos de Lima (1996), é justamente a interpenetração aquilo que permite a emergência da virtualidade que está no "eu", virando-o pelo avesso. Para além da possibilidade sempre virtual de reversibilidade entre pontos de vista coexistentes, tal como argumentado por Viveiros de Castro $(2002,2015)$ para o caso amazônico, a bruxaria Mapuche alinhase à disputa entre pontos de vista, ou dos pontos de vista em luta para ditar os termos de um evento.

O diálogo é, mais uma vez, com Lima (1996): na simetria perspectiva entre a caça (para os Yudjá) e a guerra (para os porcos), há uma querela política e enunciativa pela sobreposição do lugar de sujeito 
e, neste sentido, de um ponto de vista. Dessa disputa depende a vida e/ou a capacidade do sujeito de se reconhecer como tal entre os seus. A morte na caça faz do caçador um guerreiro abatido e, neste sentido, um virtual porco que se atualiza, como o Mapuche que sofre de awinkamiento e, se não tratado, morre para as pessoas de verdade e se torna um wekuve colonial ou um winka: devém um diferente. Daí que as relações entre coletivos - entre Mapuche, winka e espíritos, por exemplo - seja o efeito cumulativo de relações entre pessoas (COURSE, 2008, p. 316); as pessoas antecedem os grupos na medida em que estes são consequências delas. Pensar algo como uma política identitária Mapuche implicaria, então, "seguir pessoas", nos termos de Latour (2012), para entender a extensão das relações a partir das quais se forma o seu mundo. $O$ ponto de vista das pessoas de verdade emerge, portanto, de um modo distinto de relacionalidade na composição de coletivos que está vinculado às redes daquilo que entendemos como parentesco (RAMOS, 2008, p. 58).

Isso implica que as muitas ameaças ao território das comunidades rurais Mapuche pela construção de autoestradas e de hidroelétricas, pelo desmatamento acelerado dos seus bosques por empresas madeireiras, pela perda de terra nativa, pela insegurança laboral e pelo empobrecimento generalizado estão diretamente associadas à extensão do awinkamiento (cf. BACIGALUPO, 2007; BONELLI; GONZÁLEZ GÁLVEZ, 2016). Em primeiro lugar, ele não só tem as mesmas origens que as próprias ameaças, a sociedade winka e o Estado chileno que participam como aceleradores da política de espoliação colonial, como os próprios chilenos podem ser entendidos como bruxos, capazes de manipular os poderes do Catolicismo, do militarismo e do Estado para seu benefício próprio e a despeito dos modos de vida, da socialidade e da territorialidade Mapuche. Em segundo lugar, o awinkamiento, se não devidamente tratado, promove a dispersão e enfraquece a capacidade das comunidades de resistir à captura e ao encapsulamento promovidos pelo Estado e pelo sistema do capital. Isto se dá, tanto pela corrosão das redes de reciprocidade conformadas pelas pessoas de verdade, quanto por um esvaziamento territorial.

O awinkamiento atinge pessoas e territórios, de modo que o avanço do modo de vida chileno (ou do ponto de vista winka) implica no desaparecimento dos senhores dos bosques, dos espíritos da fontes de água e de outras entidades não-humanas que conformam o Wallmapu (território Mapuche), muitos deles conhecidos como gen (donos ou controladores). Em mundos altamente relacionais, em que pessoas se compõem de relações, não preexistindo a elas, a modificação de um campo relacional (material e pragmático) permite a latência e a atualização de uma multiplicidade ontológica (BONELLI; GONZÁLEZ GÁLVEZ, 2016, p. 34), levando à composição de novas conexões, novas relações e, por conseguinte, de novos acoplamentos entre entidades. Nas palavras do chefe Mapuche e antropólogo Quidel Lincoleo,

Los Mapuche no sólo vivimos nuestra vida, sino que también las demás vidas viven en nosotros. Formamos una cadena cósmica con los seres del mundo. Tanto con 
los espirituales como los materiales. De ahí que haya que tener cuidado extremo en la convivencia con la multiplicidade de habitantes del cosmos (RODRÍGUEZ; QUIDEL LINCOLEO, 2016, p. 130).

Em termos do atual debate antropológico, a disputa entre o awinkamiento e a sua cura pode ser entendida como uma "guerra ontológica", um processo de destruição de redes-de-vizinhança que coloca em seu lugar redes-de-mercado (ALMEIDA, 2013, p. 20); uma guerra de mundos (cf. LATOUR, 2002) que põe em risco a reprodução pragmática dos existentes. A expansão do mundo moderno/colonial/patriarcal/capitalista do awinkamiento coloca em risco a reprodução dos elementos que constituem e condicionam a vida Mapuche na medida em que transforma as condições de existência do seu mundo em matéria-prima para a produção de mercadorias e para a expansão do mundo do capital, tal como já nos alertava a crítica xamânica de Davi Kopenawa (cf. KOPENAWA; ALBERT, 2015).

Se a bruxaria do awinkamiento aponta para a divisão e a incompreensão, a saúde se refere ao compor uma unidade, ainda que sempre virtual. Conforme argumenta Course (2011), no núcleo da noção Mapuche de saúde e bem-estar está uma dialética da pessoa que diz respeito às formas das relações sociais nas quais devem participar os Mapuche para que sejam pessoas de verdade e através das quais são nutridas e formadas. Curar, neste contexto, implica que o paciente seja capaz de tornar a produzir coletivo com outras pessoas de verdade, produzindo unidades e conformando redes de reciprocidade. A cura é o que permite às pessoas recobrarem o controle das suas vidas e produzir alianças afetivas, a ser parente.

O que aqui chamamos de cura é o resultado de uma limpeza corporal executada pelas machi, as xamãs Mapuche, através de operações como o datun, entre outros, considerado pela literatura como um "ritual xamânico de cura" (cf. BACICALUPO, 2007). As machi, nomeadas aqui no feminino para colocar ênfase no importante papel desempenhado por uma expressiva quantidade de especialistas rituais mulheres (QUIDEL LINCOLEO, 1998), são aquelas capazes de participar na canalização das forças que permeiam e animam o cosmos. As xamãs medeiam as relações entre o humano e os mundos espirituais, e entre os discursos de tradição e modernidade, entre outras coisas. De forma geral, os xamanismos ameríndios têm sido caracterizados como instâncias de mediação (cf. CARNEIRO DA CUNHA, 1998; CESARINO, 2011 ; SZTUTMAN, 2013; VIVEIROS DE CASTRO, 2002), isto é, como uma tecnologia através da qual se leva a cabo uma sorte de diplomacia cósmica entre diferentes esferas ontológicas. No contexto Mapuche, se o awinkamiento se conforma como um processo de perda de si mesmo relacionado com os avanços das forças coloniais, a ação das machi é, num sentido inverso, uma política de descolonização. Elas se valem de suas habilidades cósmicas, de suas relações com os espíritos-guia (machi püllü), para produzir e administrar a identidade Mapuche enquanto resistem às 
práticas e às ideologias do Estado-nacional chileno e da modernidade capitalista, colonial e patriarcal.

Neste sentido, e no que diz respeito às concepções ontoepistêmicas Mapuche, a chave para se explorar as relações entre colonialismo e descolonização está na dinâmica entre cura e bruxaria, saúde e doença, tomando-as na relação entre cosmologia, força vital e a noção de pessoa e coletivo. Aqui, o Estado e o capitalismo se tornam uma força agressiva, um perigo de anulação dos possíveis e da multiplicidade. Como toda força no mundo Mapuche, eles também são uma presença ${ }^{19}$. Neste sentido, a resistência a eles se torna um modo de afirmar existências diversas e de criar novos possíveis ao mesmo tempo em que se protege a pessoa, fazendo com que se habite e se conheça a partir do ponto de vista Mapuche.

\section{Palavras finais}

Se no caso da teoria crítica os pressupostos descansam sobre o conhecimento das coisas, o xamanismo Mapuche está interessado em entender relações entre pessoas (como categoria ampla que abarca entidades relacionais, inclusive aquelas que entendemos como coisas, animais e espíritos). No primeiro caso, importa o que se faz com as relações, no segundo, o que as relações fazem com as pessoas. Assim, se neste último caso as pessoas são microcosmos de relações, a descolonização é uma contra-ação extensiva e intensiva. Em suma, os pressupostos que animam o pensamento da teoria crítica, por um lado, e aqueles que alimentam a prática xamanística da teoria Mapuche, por outro, são fundamentalmente dissimilares entre si. Neste sentido, a priorização de alguns elementos sobre outros também se diferem em cada caso.

No entanto, parece haver uma certa coincidência, ainda que de superfície, entre ambas: o colonialismo/awinkamiento é um fenômeno interno e externo, intensivo e extensivo, encontrando-se nas pessoas como dobra do mundo, e no mundo como resultado de pessoas. Se é a colonialidade, como aponta Quidel Lincoleo (2016, p. 714), que impede que se vislumbre a possibilidade de uma autonomia Mapuche, isso se deve ao fato de que tal fenômeno seja político em sua acepção mais própria: na capacidade de reordenar a distribuição do sensível, do visível, do pronunciável e do dizível, isto é, de afirmar o que é, o que existe e o que pode ser discutido (cf. RANCIÈRE, 2018), e isto diz respeito à uma dinâmica de extensividade e intensividade.

Como bem coloca Sztutman (2018, p. 347), "a pretensa invencibilidade do capitalismo estaria refletida na sua capacidade de surpreender oponentes, de tirar lucro de qualquer oportunidade, tirar proveito de qualquer desatenção, de produzir, enfim, a impotência nas pessoas". Resistir a ele implicaria, portanto, ampliar nosso campo de

\footnotetext{
${ }^{19}$ Ver, por exemplo, a exploração da força newen em Pineda Ramírez (2018), Course (2011) Bonelli e González Gálvez (2016), entre outros.
} 
atenção e multiplicar nossas alianças, compor com Gaia, com a Pachamama e com muitas outras entidades que povoam nossos mundos transtocados pela potência do capital. É preciso precaver-nos e estar atentos. Na cura Mapuche, voltar a conformar com o mundo implica reapropriar-se da capacidade de produzir relações adequadas com outras pessoas de verdade, isto é, de reativar vínculos antes perdidos ou inexistentes, e produzir, como resultado, uma miríade de sujeitos possíveis. A isso Stengers chama de "empoderamento", ainda que prefiramos, aqui, chamá-lo de autonomia, seguindo a opção política dos companheiros Mapuche. A autonomia é a capacidade de produzir relações que escapem à captura do Estado e do capital, de precaver-se e ter condições de deslindar-se do seu marco de referências. Se para se sobrepor, o capitalismo ataca nossa capacidade política de imaginar e compor mundo com outros existentes, desobrigando-nos a pensar (cf. PIGNARRE; STENGERS, 2005; SZTUTMAN, 2018), é a abertura aos impensáveis que permite criar alianças afetivas através de mundos de diferença, compondo resistências que, ao acoplar múltiplas constituições onto-epistêmicas, produzam lutas pós-orgânicas, parciais e ciborgues, que se dão em escala de incomensurabilidades mas permitem habilitar capacidades antes inimaginadas.

O desafio inicial é, no entanto, o de superar a gramática do colonialismo interno, aquela que transforma possíveis aliados em seres tutelares ou inexistentes, ou em alvos de nosso pensamento dito privilegiado. É neste sentido que uma resistência anti-feiticeira, que atua de forma "extraordinária", implicaria também um desafio à tradicional gramática das resistências de esquerda, da crítica sociológica e historiográfica ao capitalismo e ao colonialismo e da nossa forma de produzir teoria como pensamento. É preciso, pois, descolonizar nossa forma de produzir crítica para que estejamos aptos a produzir alianças. É preciso alinhar-nos com as xamãs Mapuche e seus espíritos-guia, com os xapire da floresta Yanomami, com o Tepeyolot das montanhas nahuas e com os orixás das nossas religiões de matriz africana, mas antes disso, precisamos criar espaço para eles em nossa noção de política, de crítica e, sobretudo, de descolonização. 


\section{Referências Bibliográficas}

ALMEIDA, M. W. B. De. Caipora e outros conflitos ontológicos. R@u: Revista de Antropologia da UFSCar v. 5, n. 1, p. 7-28, 2013.

BACIGALUPO, A. M. Shamans of the foye tree: gender, power, and healing among the Chilean Mapuche. Austin: University of Texas Press, 2007.

BONELLI, C.; GONZÁLEZ GÁLVEZ, M. ¿Qué hace un camino? Alteraciones infraestructurales en el Sur de Chile. Revista de Antropologia v. 59, n. 3, p. 18-48, 2016.

BONFIL BATALLA, G. Historias que no son todavía historia. In: PEREYRA, Carlos (Org.). Historia, ¿para qué? México: Siglo XXI Editores, 1980. p. 227-245.

CARNEIRO DA CUNHA, M. Pontos de vista sobre a floresta amazônica: xamanismo e tradução. Mana v. 4, n. 1, p. 7-22, 1998.

CASTRO-GÓMEZ, S; GROSFOGUEL, R. Prólogo. Giro decolonial, teoría crítica y pensamiento heterárquico. In: CASTRO-GÓMEZ, S.; GROSFOGUEL, R. (Orgs.). El giro decolonial: reflexiones para una diversidad epistémica más allá del capitalismo. Bogotá: Siglo del Hombre Editores: Universidad Central: Pontificia Universidad Javeriana, 2007. p. 9-24.

CESARINO, P. de N. Oniska: poética do xamanismo na amazônia. São Paulo: Perspectiva: Fapesp, 2011.

CLAROS, L. Colonialidad y violencias cognitivas. Ensayos político-epistemológicos. La Paz: Muela del Diablo Editores, 2011.

COELHO DE SOUZA, M. Por que a identidade não pode durar. A troca entre LéviStrauss e os índios. In: QUEIROZ, Ruben Caixeta De; NOBRE, Renarde Freire (Orgs.). Lévi-Strauss: leituras brasileiras. Belo Horizonte: Editora UFMG, 2013. p. 289-328.

COURSE, M. Becoming mapuche. Person and ritual in indigenous Chile. Chicago: University of Illinois Press, 2011.

COURSE, M. Estruturas de diferença no palin, esporte mapuche. Mana v. 14, n. 2, p. 299-328, 2008.

DE LA CADENA, M. Earth Beings: Ecologies of Practice across Andean Worlds. Durham \& London: Duke University Press, 2015.

DE LA CADENA, M. Indigenous cosmopolitics in the Andes: conceptual reflections beyond "politics". Cultural Anthropology v. 25, n. 2, p. 334-370, 2010.

DELEUZE, G. A dobra: Leibniz e o Barroco. Campinas: Papirus, 1991. 
Espaço Ameríndio

DELEUZE, G; GUATTARI, F. Mil platôs: capitalismo e esquizofrenia 2. Volume 1. São Paulo: Editora 34, 2011.

DUSSEL, E. 1492. El encubrimiento del otro. Hacia el origen del "mito de la modernidad". La Paz: Biblioteca Indígena: Vicepresidencia del Estado Plurinacional de Bolivia, 2008.

DUSSEL, E. Europa, modernidad y eurocentrismo. In: LANDER, E. (Org.). La colonialidad del saber: eurocentrismo y ciencias sociales. Perspectivas Latinoamericanas. Buenos Aires: CLACSO, 2005. p. 42-53.

ESCOBAR, A. Autonomía y diseño. La realización de lo comunal. Buenos Aires: Tinta Limón, 2017.

FEDERICI, S. Calibã e a bruxa: mulheres, corpo e acumulação primitiva. São Paulo: Editora Elefante, 2017.

FLAKSMAN, Cl. Culpa e cuidado no candomblé baiano. Revista do Instituto de Estudos Brasileiros n. 69, p. 307-323, 2018.

FOUCAULT, M. Em defesa da sociedade. Curso no Collège de France (1975-1976). São Paulo: Martins Fontes, 1999.

GARIBAY OROZCO, C. Paisajes de acumulación minera por desposesión campesina en el México actual. In: DELGADO, G. C. (Org.). . Ecología política de la minería en América Latina. México: Universidad Nacional Autónoma de México, 2010. p. 133181.

GONZÁlEZ CASANOVA, P. El colonialismo interno. Sociología de la explotación. Buenos Aires: CLACSO, 2006. p. 185-205.

HARVEY, D. O novo imperialismo. São Paulo: Loyola, 2003.

HOLBRAAD, M; PEDERSEN, M. A. The Ontological Turn: An Anthropological Exposition. Cambridge: Cambridge University Press, 2017.

HOLlOWAY, J. Mudar o mundo sem tomar o poder: o significado da revolução. São Paulo: Viramundo, 2003.

KOPENAWA, D; ALBERT, B. A queda do céu: palavras de um xamã yanomami. São Paulo: Companhia das Letras, 2015.

LATOUR, B. Jamais fomos modernos: ensaio de antropologia simétrica. São Paulo: Editora 34, 2013.

LATOUR, B. Quel cosmos? Quelle cosmopolitiques? In: LOLIVE, Jacques; SOUBEYRAN, O. (Orgs.). L'émergence des cosmopolitiques. Paris: La Découverte, 2007. p. 69-84.

LATOUR, B. Reagregando o social. Salvador: EDUFBA, 2012. 
LATOUR, B. War of the Worlds: What about Peace? Chicago: Prickly Paradigm Press, 2002.

LÉVI-STRAUSS, C. Antropologia Estrutural. São Paulo: Ubu Editora, 2017.

LÉVI-STRAUSS, C. História de lince. São Paulo: Companhia das Letras, 1993.

LIMA, T. S. O dois e seu múltiplo: reflexões sobre o perspectivismo em uma cosmologia tupi. Mana v. 2, n. 2, p. 21-47, 1996.

LIMA, T. S. Por uma cartografia do poder e da diferença nas cosmopolíticas ameríndias. Revista de Antropologia v. 54, n. 2, p. 601-646, 2011.

LUXEMBURGO, R. A acumulação do capital. São Paulo: Nova Cultural, 1988.

MALDONADO-TORRES, N. La descolonización y el giro des-colonial. Tabula Rasa v. 9, p. 61-72, 2008.

MARX, K. O capital, livro 1: o processo de produção do capital. Rio de Janeiro: Civilização Brasileira, 2011.

MBEMBE, A. Necropolítica. Biopoder, soberania, estado de exceção, política da morte. São Paulo: n-1 edições, 2018.

MIGNOLO, W. Colonialidade: o lado mais escuro da Modernidade. Revista Brasileira de Ciências Sociais - RBCS v. 32, n. 94, p. 1-18, 2017.

MIGNOLO, W. La idea de América Latina: la herida colonial y la opción decolonial. Barcelona: Gedisa Editorial, 2007.

MIGNOLO, W. The Darker Side of the Renaissance. Literacy, Territoriality and Colonization. Ann Arbor: The University of Michigan Press, 1995.

NAHUELPÁN, H. El lugar del "indio" en la investigación social. Reflexiones en torno a un debate político y epistémico aún pendiente. Revista Austral de Ciencias Sociales n. 24, p. 71-91, 2013.

PIGNARRE, P; STENGERS, I. La sorcellerie capitaliste. Pratiques de désenvoûtement. Paris: Éditions La Découverte, 2005.

PINEDA RAMÍREZ, C E. Arde el Wallmapu. Autonomía, insubordinación y movimiento radical mapuche en Chile. México: Centro de Investigaciones sobre América Latina y el Caribe: Universidad Nacional Autónoma de México: Bajo Tierra A.C., 2018.

QUIDEL LINCOLEO, J. El quiebre ontológico a partir del contacto mapuche hispano. Chungara, Revista de Antropología Chilena v. 48, n. 4, p. 713-719, 2016.

QUIDEL LINCOLEO, J. Machi Zugu: Ser Machi. CUHSO - Cultura - Hombre - 
Espaço Ameríndio

Sociedad v. 4, n. 1, p. 30-37, 1998.

QUIJANO, A. Colonialidad del poder, eurocentrismo y América Latina. In: LANDER, E. (Org.). La colonialidad del saber: eurocentrismo y ciencias sociales. Perspectivas Latinoamericanas. Buenos Aires: CLACSO, 2000a. p. 201-245.

QUIJANO, . Colonialidade del Poder y Clasificación Social. Jounal of World-Systems Research v. VI, n. 2, p. 342-386, 2000 b.

RAMOS, A. El nawel y el pillañ. La relacionalidad, el conocimiento histórico y la política mapuche. World Anthropologies Network E-Journal v. 4, p. 57-79, 2008.

RANCIÈRE, J. O desentendimento. São Paulo: Editora 34, 2018.

RIVERA CUSICANQUI, S. Ch'ixinakax utxiwa. Una reflexión sobre prácticas y discursos descolonizadores. Buenos Aires: Tinta Limón, 2010.

RODRÍGUEZ, J. M.; QUIDEL LINCOLEO, J. Discusión sobre la presencia de la brujería europea y del chamanismo mapuche en un relato de Marta Brunet. Acta Literarua v. 53, p. $127-153,2016$.

SCHAVELZON, S. Cosmopolítica y yuxtaposición en la propuesta de Estado Plurinacional de Bolivia. Revista Chilena de Antropología v. 33, n. 1, p. 87-101, 2016.

SPIVAK, G. C. Pode o subalterno falar? Belo Horizonte: Editora UFMG, 2014.

STENGERS, I. La proposition cosmopolitique. In: LOLIVE, Jacques; SOUBEYRAN, O. (Orgs.). L'émergence des cosmopolitiques. Paris: La Découverte, 2007. p. 45-68.

STRATHERN, M. O gênero da dádiva: problemas com as mulheres e problemas com a sociedade na Melanésia. Campinas: Editora da Unicamp, 2009.

SVAMPA, M. Extractivismo neodesarrollista y movimientos sociales. ¿Un giro ecoterritorial hacia nuevas alternativas? In: LANG, M; MAKRANI, D. (Orgs.). . Más allá del desarrollo. Grupo Permanente de Trabajo sobre Alternativas al Desarrollo. Quito: Ediciones Abya-Yala: Fundación Rosa Luxemburg, 2012. p. 185-216.

SZTUTMAN, R. Metamorfoses do Contra-Estado: Pierre Clastres e as Políticas Ameríndias. Ponto Urbe v. 13, p. 1-22, 2013.

SZTUTMAN, R. Reativar a feitiçaria e outras receitas de resistência - pensando com Isabelle Stengers. Revista do Instituto de Estudos Brasileiros n. 69, p. 338-360 , 2018.

TAUSSIG, M. O diabo e o fetichismo da mercadoria na América do Sul. Sāo Paulo: Editora da Unesp, 2010.

TAUSSIG, M. Xamanismo, colonialismo e o homem selvagem: um estudo sobre o terror e a cura. Rio de Janeiro: Paz e Terra, 1993.

TIBLE, J. Marx selvagem. São Paulo: Autonomia Literária, 2017.

TODOROV, T. Nosotros y los otros: reflexión sobre la diversidad humana. México: 
Espaço Ameríndio

Siglo XXI Editores, 1991.

VANZOLINI, M. O feitiço e a feitiçaria capitalista. Revista do Instituto de Estudos Brasileiros v. 69, n. abr, p. 324-337, 2018.

VIVEIROS DE CASTRO, E. A inconstância da alma selvagem e outros ensaios de antropologia. São Paulo: Cosac Naify, 2002.

VIVEIROS DE CASTRO, E. Gut feelings about Amazonia: potential affinity and the construction of sociality. In: RIVAL, L; WHITEHEAD, Neil (Orgs.). . Beyond the visible and the material: the amerindianization of society in the work of Peter Riviere. Oxford: Oxford University Press, 2001. p. 19-43.

VIVEIROS DE CASTRO, E. Metafísicas canibais: elementos para uma antropologia pós-estrutural. São Paulo: Cosac Naify, 2015.

VIVEIROS DE CASTRO, E. Os pronomes cosmológicos e o perspectivismo ameríndio. Mana v. 2, n. 2, p. 115-144, 1996.

WAGNER, R. A invenção da cultura. São Paulo: Cosac Naify, 2012.

WAGNER, R. A pessoa fractal. Ponto Urbe v. 8, p. 1-14, 2011.

WALSH, C. (Post)Coloniality in Ecuador: The Indigenous Movement's Practices and Politics of (Re)Signification and Decolonization. In: MORAÑA, M; DUSSEL, E; JÁUREGUI, C. A. (Orgs.). . Coloniality at Large: Latin America and the Postcolonial Debate. Durham \& London: Duke University Press, 2008. p. 506-518.

WALSH, C. Pedagogías decoloniales: prácticas insurgentes de resistir, (re)existir y (re)vivir. Tomo I. Quito: Ediciones Abya-Yala, 2013.

WALSH, C. Pedagogías decoloniales: prácticas insurgentes de resistir, (re)existir y (re)vivir. Tomo II. Quito: Ediciones Abya-Yala, 2017. 